Contemporary Genre Studies: An Interdisciplinary Conversation with Johannine Scholarship

Auken, Sune

Published in:

The Gospel of John as Genre Mosaic

Publication date:

2015

Document version

Version created as part of publication process; publisher's layout; not normally made publicly available

Citation for published version (APA):

Auken, S. (2015). Contemporary Genre Studies: An Interdisciplinary Conversation with Johannine Scholarship. In K. B. Larsen (Ed.), The Gospel of John as Genre Mosaic (pp. 47-66). Vandenhoeck \& Ruprecht. Studia Aarhusiana Neotestamentica Vol. 3 


\section{Contemporary Genre Studies: An Interdisciplinary Conversation with Johannine Scholarship}

In order to grasp the state of contemporary genre studies one must recognize that literary scholarship has long been out of vogue. Scholars of literature may have defined the subject for many years, but those days are long gone. From the mideighties onwards, literary genre studies has stalled, whereas linguistic, rhetorical, and didactic genre studies have flourished-the dominant subject in genre studies these days is, in fact, writing studies, with ethnographic and sociological subjects following close on its heels. There is still interesting work being done among literary scholars, and I will marginally touch upon some of it here, but compared to the cohesiveness and impact achieved in the other fields, literary genre studies has fallen behind.

However, much remains to be done. Whereas genre as a phenomenon is omnipresent in human culture, understanding and communication, genre studies is not as prolific. It is a specific and highly specialized scholarly endeavour that may be very well developed but is not universally known, or even well-known in academia. Thus, you may live, study, interact with, and even research genres throughout your life without ever giving a thought to the existence of a cohesive body of knowledge concerned with the subject. Consequently, not only do scholars often discuss questions of genre without knowing the state of the art in genre studies; they may make discoveries which have already been made in genre studies and proclaim them as breakthroughs (bad), or make new discoveries relevant to genre studies without news of these developments ever reaching genre studies (worse).

Thus, the purpose of this article is to contribute to the mediation between contemporary genre studies and scholars from other fields who work with genre; in casu: Biblical scholars working with the Gospel of John. So it will present some of the developments in current genre theory and suggest some ways in which these may be worked into the interpretative practices in literary and biblical studies. These remarks are of a general nature and not aimed immediately at John. In order to illustrate a few of the points, the article will also attempt a tentative reading of one passage from John. This reading is only included for 
illustration. It is clearly literary in character, and has no claim to profoundness or originality in biblical studies.

\section{The Social Function of Genre}

The defining moment in modern genre studies is the publication of Carolyn Miller's "Genre as Social Action" from 1984. ${ }^{1}$ This article forms a watershed because, retrospectively, it marks the point when genre studies moved from being a primarily literary and aesthetic to a rhetorical, linguistic, didactic, and, broadly speaking, interdisciplinary endeavour. Also, it gives a distinct character to the direction genre studies has taken over the last thirty years. There are several theoretical positions formulated in contemporary genre studies, none of them literary - the description presented by Sunny Hyon in 1996 still seems to hold ${ }^{2}-$ but I am going to focus mainly on North American Rhetorical Genre Studies, or RGS. It is the most influential of the different positions, and also the one that traces its descendance most directly to Miller.

"Genre as Social Action" is central within genre studies for presenting a rhetorical definition of genre which has later become fundamental not just in the rhetorical field, but within genre studies in general, its basic assumptions being rarely challenged. Later researchers have, however, applied, deepened, expanded, systematized, and clarified the basic tenets, adding knowledge and demonstrating just how powerful the original position was. ${ }^{3}$

Miller's rhetorical understanding of genre has had its most fundamental impact on genre studies on two points: Genres are seen as functional, and the de facto genres of everyday life have become the predominant subject in genre studies. Today, the functional perspective on genre is so dominant that it not only heuristically determines the work done with genre in Rhetorical Studies, but is seen as defining for what genre is: The number of times Miller's definition of

1 Carolyn Miller, “Genre as Social Action,” Quarterly Journal of Speech 70 (1984): 151-167.

2 Sunny Hyon, "Genre in Three Traditions: Implications for ESL", TESOL Quarterly 4 (1996): 863-722. For more on the state of modern Genre Studies see also Anis Bawarshi and Mary-Jo Reiff, Genre. An Introduction to History, Theory, Research, and Pedagogy (Fort Collins: Parlor Press, 2010), as well as Sune Auken, "Utterance and Function in Genre Studies: A Literary Perspective," in Genre Theory in Information Studies, ed. J. Andersen, Studies in Information 11 (Bingley: Emerald Group, 2015), 155-178; and Anne Smedegaard, "Genre and Writing Pedagogy", in Genre and ..., ed. S. Auken, P. S. Lauridsen, and A. J. Rasmussen, Copenhagen Studies in Genre 2 (Copenhagen: Ekbatana, 2015), 21-55.

3 Notable for raising some criticism is Inger Askehave and John Swales, "Genre Identification and Communicative Purpose," Applied Linguistics 2 (2001): 195-212, and Amy Devitt, "ReFusing Form in Genre Study," in Genres in the Internet, ed. J. Giltrow and D. Stein (Philadelphia: John Benjamins, 2009), 27-48. 
genre as "typified rhetorical actions based in recurrent situations" (159) is used in modern genre studies is staggering. At the same time, the subject matter of genre studies has shifted, and the analysis of the genres in use (everyday genres), has taken centre stage. The high rhetorical genres of oratory are pushed into the background, literary genres are all but gone, and with them also most of what was done in literary genre theory. In hindsight, this development is unsurprising. It allows genre researchers a wider field of study, enables active interaction with other fields of research and with society at large, and in effect gives genre studies a much more extensive impact than had hitherto been the case.

Genres arise to carry out certain social functions; they are typified answers to recurrent situations. Basically: You discover that in a given situation, acting in a particular way will achieve a particular social purpose, and so a pattern (genre) is established. If you need a job, you write an application; if you want soldiers to attack, you give out an order etc. etc. This means that the function determines the genre. Genres are ways to do things with typified words. They are social actions.

The point of this interest in the social function of everyday genres is that it allows genre studies to track the impact and the use of genre in our social life, in organisations, and in activity systems. It shows how our interactions form genres, how genres form our interactions, how we are socialized into generic patterns, and how we use genres to achieve our social purposes both on an individual and on an institutional level. ${ }^{4}$ Almost everything of note that has happened in genre studies the last three decades is centred on this social and functional perspective - even in those branches of genre scholarship that do not trace their origin as directly to Miller as does RGS. So it is characteristic of contemporary genre studies that it moves the interest of the field in exactly the opposite direction of the literary genre approach, as it emphasizes the functions of genre, but not the actual utterances that are crucial to text based fields like literary or biblical studies.

4 The available literature on genre use in institutions is quite overwhelming. A very modest selection includes Amy Devitt, "Intertextuality in Tax Accounting: Generic, Referential and Functional," in Dynamics of the Professions: Historical and Contemporary Studies in Writing in Professional Communities, ed. C. Bazerman and J. Paradis (Madison: University of Wisconsin, 1991), 291-303; Charles Bazerman, "Systems of genres," in Genre and the New Rhetoric, ed. A. Freedman and P. Medway (London: Taylor \& Francis, 1994), 79-101; David R. Russel, "Rethinking Genre in School and Society: An Activity Theory Analysis," Written Communication 4 (1997): 504-554; Natasha Artemeva, "Approaches to Learning Genres: A Bibliographical Essay," in Rhetorical Genre Studies and Beyond, ed. N. Artemeva and A. Freedman (Winnipeg: Inkshed, 2008), 9-99; and Jack Andersen, "Re-Describing Knowledge Organization : A Genre and Activity-Based View", in J. Andersen, Genre Theory in Information Studies, 13-42. 


\section{Five Basic Tenets of Genre Studies}

Since literary genre studies has been slow to progress in the last three decades, working with the new understandings of genre put forth in RGS and its modern compatriots in genre studies is not a matter of individual choice. We need to understand what has happened within the field, even if we want to challenge its state of the art. Otherwise we may well be working with a concept called "genre," but unrelated to the meaning of the word in current scholarship. A refusal to deal with the new research situation thus means making ourselves redundant in genre studies.

However, if we want to engage with contemporary genre studies, we need some reasonably coherent understanding of its state of the art. Therefore, I shall, in the following pages, lay out five points that present the fundamental tenets of contemporary genre studies, and then four points that approximate some of the central interpretative consequences of those tenets (see section 3).

First: Genres are omnipresent in culture. What is usually treated as genres in literary theory is, in fact, a very special case of genre practice. Even a very broad (and nefariously vague) genre category like "the literary work" is just one specialized version of a genre. Genres are not just found in literature; genres are everywhere in culture. All our social interactions are guided by generic patterns (they are, so to speak, "genred"); ${ }^{5}$ our perception, categorization, and interpretation of cultural phenomena are informed by genres-and by our understanding of how genres work. Thus every extended use of language, and even the overwhelming majority of brief uses, oral or written, will be structured by genre. And genres are not even limited to language. There are genres in film, painting, dance, architecture-and even for that matter in tea, food, and handbags. The naming of the genre will always be in language, of course, but you do not need to know the name or any definition of a genre in order to use and understand it. Most research at the core of genre studies focuses on textual genres, ${ }^{6}$ and, as mentioned, there is a close connection between genre studies and writing studies

5 Catherine Schryer, "Genre and Power. A Cronotopic Analysis," in The Rhetoric and Ideology of Genre, ed. R. Coe, L. Lingard, and T. Teslenko (Cresskill: Hampton, 2002), 95.

6 See for instance Dorothy A. Winsor, "Ordering Work. Blue-Collar Literacy and the Political Nature of Genre," Written Communication 17 (2000), 155-184; Anis Bawarshi, Genre and the Invention of the Writer (Logan: Utah State University Press, 2003); Vijay K. Bhatia, Worlds of Written Discourse (London: Continuum, 2004); Amy Devitt, Writing Genres (Carbondale: Southern Illinois University Press, 2004); and Anthony Paré, Doreen Starke-Meyerring and Lynn McAlpine, "The Dissertation as Multi-Genre: Many Readers, Many Readings," in Genre in a Changing World, ed. C. Bazerman, A. Bonini, and D. Figueiredo (Fort Collins: Parlor, 2009), 179-193; John Swales, Research Genres (Cambridge: Cambridge University Press, 2004). 
that merits closer attention, ${ }^{7}$ even if its textual focus may somewhat skew the perception of genre. Within this field, however, there is an expansive research effort covering texts from a wide array of genres. Moreover there is a detailed knowledge of the manifold different ways in which our communication and understanding is conditioned by genre.

Second: Genres owe a large part of their proliferation and strength in culture to a combination of regulation and innovation. Genres form comprehensible patterns that can be carried over from situation to situation and from utterance to utterance, and that can, if needed, act normatively in new situations. At the same time, however, genres are also extremely flexible. Every new usage of a genre adds to or subtracts from the genre, manipulates it, gives it a new meaning, a new focus, a new context, a new form, or a new content. This is true even for strongly normative genres like those of the juridical system: laws, directives, ministerial orders, sentences, etc. As the situation to be regulated by the law often varies from one instance to the next, the application of the genres of law have to be modified accordingly. ${ }^{8}$

The point is that genres are so prolific in human culture because they are not monolithic, but simultaneously firm and flexible. They can frame and control any given situation, while also leaving room for creative actions and uptakes by individual genre users. The most famous description of this in contemporary genre studies is Catherine F. Schryer's declaration that genres are stabilized for now, or stabilized enough to allow for understanding, action and coherent communication. ${ }^{9}$ Amy Devitt, another of the captains of modern genre studies, has suggested against Schryer that "genres are not even stabilized for now, as they live and breathe through individual instances and interactions across and within genres." ${ }^{10}$ Devitt's point is that each instance of genre use will always somehow modify the genre, and thus cannot be reduced to, or adequately described in terms of, the genre or genres involved. For the very same reason individual

7 Thus a number of the central texts on genre have been developed and published through the so-called Writing Across the Curriculum Clearinghouse (http://wac.colostate.edu/index. cfm).

8 Thus one of the fundamental tenets of Danish legal practice is the principle that one must not "sætte skøn under regel" (bind the assessment with rules), the point being that the use of a reasoned assessment by the person making the ruling is not only allowed but required, and that the individual traits of any given situation must not be neglected when deciding how a given legal rule applies to it.

9 Catharine Schryer, "Records as genre," Written Communication 10 (1993): 208. Cf. Catharine Schryer, "The Lab vs the Clinic," in A. Freedman and P. Medway, Genre and the New Rhetoric, 108.

10 Amy Devitt, "Re-fusing Form," 39. 
genres, too, cannot be put on a simple formula. So, their organizing and categorizing functions aside, genres both regulate and liberate users. ${ }^{11}$

Third: Genres do not exist in isolation, but form larger patterns including other genres. Current genre studies has developed a nuanced vocabulary describing different levels and forms of relationships between genres: "genre set," 12 "genre chain,"13 "genre system,"14 "genre repertoire,"15 and "genre ecology,"16 to name but a few central ones. Charting out the interrelationship and the hierarchies between genres, these concepts allow us to see how, for instance, organisations get things done through patternings of genre, and through distributions of genre sets on different roles within the system.

Within the general area of genre patterns, one concept in particular seems relevant for us: the concept of uptake, introduced in genre studies by Anne Freadman who has it from the language philosopher J. L. Austin's famous How to Do Things With Words. ${ }^{17}$ It may probably be seen as putting Miller's concept of genre as social action into motion. Uptake dynamizes social action. Miller describes how genres are used for actions in concrete situations and sketches out some of the principles on a general level. Freadman describes this in a dynamic perspective, demonstrating how genres interact-and even to a certain extent: interlock-in actual communication. The point of the concept is that genres are seen as uptakes; reactions to other uses of genre. The use of a genre takes another genre use as "an invitation or a request", ${ }^{18}$ and answers it. In the words of Graham Smart, "the appearance of a text in one genre invites a responding text in the

11 Bawarshi, Genre and the Invention; Devitt, Writing Genres.

12 Devitt, "Intertextuality," 340.

13 Swales, Research Genres, 18-20.

14 Bazerman, "Systems of Genres".

15 Wanda J. Orlikowski and JoAnne Yates, "Genre Repertoire: The Structure of Communicative Practices in Organizations, "Administrative Science Quarterly, 39 (1994): 541.

16 Clay Spinuzzi and Mark Zachry, "Genre Ecologies: An Open-system Approach to Understanding and Constructing Documentation", Journal of Computer Documentation 24 (2000): 169.

17 John L. Austin, How To Do Things With Words (Oxford: Oxford University Press, 1976); Anne Freadman, "Anyone for Tennis?" in A. Freedman and P. Medway, Genre and the New Rhetoric, 43-66, Anne Freadman, "Uptake," in R. Coe et al., The Rhetoric and Ideology of Genre, 39-53. For more on uptake see Celia Roberts and Sirkant Sarangi, "Uptake of Discourse Research in Interprofessional Settings: Reporting from Medical Consultancy," Applied Linguistics 24 (2003): 338-359: Katja Thieme, "Uptake and Genre: The Canadian Reception of Suffrage Militancy," Women's Studies International Forum 29 (2006): 279-288; Kimberly K. Emmons, "Uptake and the Biomedical Subject," in C. Bazerman et al., Genre in a Changing World, 134-157; Tosh Tachino, "Theorizing Uptake and Knowledge Mobilization: A Case for Intermediary Genre," Written Communication 29 (2012): 455-476; and Heather Bastian, "Capturing Individual Uptake: Toward a Disruptive Research Methodology," Composition Forum 31 (2015): n.p.

18 Freadman, "Uptake," 40. 
second genre." ${ }^{19}$ This interchange is an uptake. The new use of a genre in turn acts as an invitation or request, too, and thus begets further uses of genre-in effect taking part in a social perpetuum mobile. This process itself defines the genre of the utterance in question, as texts "become identified as being of a certain genre in their interaction with other texts. When a text finds a respondent, the text's generic identity can be confirmed, but it can also be modified." ${ }^{20}$ So our genre attributions are not singular; the genre of an utterance is not always fixed, and the utterer is not the sole proprietor of the genre of his or her utterance. Freadman emphasizes that the uptake is "bidirectional," it establishes a relationship between two uses of genre. ${ }^{21}$ Utterances, therefore, can be taken up as different genres than intended, for instance an attempt at giving "advice" can be taken up as an "insult."

Thus, given the creative element involved in genre use, it is unsurprising that the uptake intended by the original genre user need not be the one actually taken. There are multiple possible uptakes to most if not all uses of genre, and inviting or requesting a certain kind of generic response is not the same as getting it. Some of the invitations made by a genre may not even be desired by the user, but inherent in the genre none the less. Thus, an "application" invites a "rejection" as well as an "acceptance."

Fourth: Most of our interpretation through genre is tacit and rarely understood as generic interpretation. ${ }^{22}$ Growing up in a cultural context, or getting socialized into one, we acquire an extensive tacit, even unacknowledged, understanding of a wide field of genres connected to that culture. This happens through a complex process which does not necessarily entail that the norms and forms of the genres are made explicit. Thus Paré, Starke-Meyerring, and McAlpine describe how even highly experienced $\mathrm{PhD}$ supervisors are unable to explicate the generic norms of good scholarship they are trying to teach their $\mathrm{PhD}$ students: "[M]uch of the advice offered by supervisors comes from a deep discipline-specific, but inexpressible discourse knowledge. Although we are attempting to get colleagues to articulate the standards to which they hold their doctoral students, even the most experienced supervisors seem uncertain."23 This does not mean that they do not understand or master these norms, but merely

19 Graham Smart, "A Central Bank's 'Communications Strategy': The Interplay of Activity, Discourse Genres, and Technology in a Time of Organizational Change," in Writing Selves/ Writing Societies, ed. C. Bazerman and D. R. Russel (Fort Collins: The WAC Clearinghouse, 2003), 16.

20 Thieme, "Uptake and Genre," 280.

21 Freadman, "Uptake," 43.

22 See Devitt, Writing Genres; and Sune Auken, "Genre and Interpretation", in S. Auken et al., Genre and ..., 154-183.

23 Paré et al., "Dissertation as Multi-Genre," 187. 
that they have acquired them through exposure to the practice of other genre users, and from practicing them themselves, not by way of explicit genre teaching. So, most of our understanding of genres is learned through practice, and is tacit, even unrecognised, as genre knowledge. We are able to perform highly complex interpretative moves through genres without realizing that we are interpretingmuch less that we are interpreting through genre. ${ }^{24}$

It is an interesting fact about this surprisingly advanced, tacit interpretation that even explicating the implied interpretations at play in any given use of genre is an independent analytical task. Consequently, generic interpretation may to a certain extent be considered as a form of re-interpretation: A conscious charting of what is already assumed as knowledge. In a similar vein, one of the hardest things in dealing with genres from a different culture-be it foreign, historical, or both-is to understand that which is implied in any given genre use.

Closely related to this point is the fifth: Our perception of genres tends to naturalize them; probably because it depends on tacit knowledge and instantaneous recognition and understanding, Since genres are habitual, they acquire an "illusion of normalcy"; ${ }^{25}$ they are "naturalized or "just the way we do things around here," ${ }^{26}$ and they may even lead to what has been called a "cultural reproduction of ignorance," ${ }^{27}$ as misconceptions inherent in a genre is carried over from person to person without reflection. In acquiring competency in a genre system, we also integrate ourselves into genre hierarchies that are both places of power relations and carriers of ideology. This is, for instance, demonstrated in Dorothy Winsor's analysis of the work order in an engineering company ${ }^{28}$ in Anthony Paré's work on the genre use of social workers, and it is also present (outside RGS) in Peter Seitel's analysis of Haia folktales. ${ }^{29}$

This naturalization of genre begs the question whether teaching genre is a conservative measure whereby the teacher, knowingly or unknowingly, naturalizes existing ideologies and power structures to the students. ${ }^{30}$ It may also act to preserve in other ways, as it may become a done thing: "The mere existence of

24 See the examples in Auken, "Genre and Interpretation."

25 Anthony Paré, "Genre and Identity: Individuals, Institutions, and Ideology," in R. Coe et al., The Rhetoric and Ideology of Genre, 61.

26 Schryer, "Genre and Power," 76.

27 Judy Z. Segal, "Breast Cancer Narratives as Public Rhetoric: Genre itself and the Maintainance of Ignorance," Linguistics and the Human Sciences 3 (2007), 4.

28 Winsor, "Ordering Work."

29 Peter Seitel, “Theorizing Genres—Interpreting Works," New Literary History 34 (2003): 275297.

30 Amy Devitt, "Teaching Critical Genre Awareness," in C. Bazerman et al., Genre in a Changing World, 337-351. 
an established genre may encourage its continued use."31 Thus even when the practical effect of a genre has receded, the habit of using it may linger.

The implied power relations and ideologies of any given genre are not invisible in the genre; they are merely naturalized to the user. Analytically speaking, an interpretation of the ways in which any individual or group apply genre will reveal these implied structures and facilitate an understanding of what is considered to be given and what, by comparison, is subject to debate for the genre user(s). This point is similar to the implied knowledge discussed in point four above, but the fundamental difference is that whereas the tacit knowledge in a genre is, in fact, knowledge, the assumptions which are normalized in a genre can be both erroneous and oppressive-even self-oppressive to the genre user(s).

\section{Consequences for Interpretation}

So far, this presentation remains squarely within the scope of RGS. However, in a critical reading of a complex text such as the Gospel of John, my application of the concepts outlined above diverges from the movement's usual path. Notably, this does not make the reading oppositional to or polemical against RGS. Nor does it challenge the basic assumptions of the movement. It is, however, somewhat off the beaten tracks of RGS.

First: Literary works and other hyper-complex utterances, like a gospel, are specialized cases of genre use. Most of the genre uses surrounding us are less formally and thematically complicated, more dominated by a particular social or institutional function, more regulated, and more standardized. They still leave room for individual creativity, but to a lesser degree. ${ }^{32}$ This means, obviously, that any generalization from literary genres to genres as such must be mindful of the difference. As so often before, we are dealing with a continuum, and simple literary genres are less complicated than complex rhetorical ones, but the point still warrants caution. The same caution also applies the other way around; thus, one cannot expect hyper-complex utterances to be adequately described by reference to the terminology of function-based genre studies. They will have advanced internal features that require a prolonged study of their individual formal and thematic traits.

However, the special place thus awarded to hyper-complex utterances does not entail independence from the humble genres analyzed by RGS, it simply shifts

31 Devitt, "Intertextuality," 340-41. See also Kathleen M. Jamieson, “Antecedent Genre as Rhetorical Constraint," Quarterly Journal of Speech 61 (1975): 406-415.

32 Cf. Mikhail Bakhtin, "The Problem of Speech Genres," in Speech Genres and Other Late Essays, ed. C. Emerson and M. Holquist (Austin: University of Texas Press, 1986), 64-65. 
their function. The basic point of Bakhtin's famous distinction between primary and secondary speech genres still holds: Complex genres are built from simpler genres. ${ }^{33}$ Therefore, in order to understand a complex genre, one must understand the many simple genres which constitute it. Thus, in working generically with the interpretation of a work we are both looking for the overall genre of the work in its entirety and for the embedded genres used to compile the work.

Second: All genres, not just the literary ones, are a combination of norms and creativity. There is less room for free expression when you are placing an order for a product than when you are writing a long poem. Yet, since even the de facto genres are only at best stabilized for now, it is unsurprising that genre norms do not determine every single trait of every utterance. Consequently, in studying the relationship between an utterance and its genre, we need to look for both stability and variation. They will vary to different degrees, in different ways, and you may call this variation a lot of things-like "genre bending" made famous in Johannine studies by Harold Attridge. ${ }^{34}$ But if one frames the demonstration of how an utterance deviates from its genre as a kind of revolution against the confines of that genre, one simply has not understood what genre is.

This, incidentally, is a recurrent phenomenon in modern day art criticism. Since originality - and with it: unconventionality - is highly valued in the evaluation of the arts, one way of marking a work as outstanding is to describe it as something that breaks or escapes genre norms, or cannot be grasped in the terms of genre, awarding genre the role of the boring "garde" to which the work can be "avant." However, since genres are at best stabilized for now, using generic norms innovatively or against the grain is a common, everyday occurrence, and the perceived escape from generic norms is therefore less than surprising. Many of the interpretative moves made in demonstrating how this or that work of art breaks away from generic norms, are original, profound, and enlightening, but the discovery itself is old as the hills.

Third: One of the fundamental influences from Miller is her vested interest in the de facto genres. The ones she terms "humble". Her interest here is one of the

33 The primary weaknesses of the distinction are two-fold. First, the notion of the primary speech genre is ill defined. A primary speech genre is "simple" (Bakhtin, "Speech Genres," 61) and takes form "in unmediated speech communication" (62). However, of the genres, he mentions, "rejoinders in everyday dialogue" and "private letters," one is written. The article never addresses this apparent contradiction, and offers no further explanation. Second, the model is too simplistic; the actual dynamic of building complex utterances out of simpler utterances is a many layered, complex process, often allowing complex genres, themselves consisting of simpler genres, to be building blocks in even more complex genres. The insight which is expressed in the distinction, however, is valid: the fundamental realisation that simple genres are the building blocks of more complex genres, and that the character and function of the simple genres change when they are embedded in more complex genres.

34 Harold Attridge, "Genre Bending in the Fourth Gospel," JBL 121 (2002): 3-21. 
most profound influences in modern genre studies, as it opens up the entire field of inquiry that defines contemporary genre research. Following her lead, genre scholars have studied tax accounting, conference paper proposals, engineer work orders, scientific papers, etc. Interest no longer rests with the literary genres, and only marginally with the high rhetorical ones. Literary or biblical scholars, obviously, cannot transform their material into de facto genres like those described by Miller. However, we can shift our field of attention to include the function of the de facto genres in the works we are treating. Even a text laden with high meaning, like John's Gospel, will incorporate numerous instances of much more ordinary genres than the high rhetorical speeches of Jesus. An RGS inspired approach would turn its attention to the more humble genres in the Gospel, the genres used not in the impressive pieces of oratory spread throughout the Gospel, but in the formally more mundane, or at least less aloof, exchanges between Jesus and his followers, Jesus and his opponents, or any other combination of people interacting throughout the Gospel.

Fourth: Taking up the interest of RGS in the functional, rhetorical or social aspects of genre, we might ask some of the same questions about the uses of genres within the frames of John's Gospel that Miller would ask of genres in social life. I have previously sketched out how such an approach might work in a study of fiction, ${ }^{35}$ and the general technique of superimposing Miller's approach on the study of the action of literary works seems feasible in the study of the Fourth Gospel as well. Looking at the actual uses of genre in John, if approaching it from an RGS point of view, one would ask a particular set of questions. One would ask as to the rhetorical situation involved, the exigence addressed by the use of genre, the recurring patterns available to the genre users, how these users employ the patterns, and thus, for the social purposes achieved (or strived for) by the concrete uses of genre.

Such an approach would activate all of the systematic and dynamic aspects of contemporary genre studies, for instance, John Swales' concept of genre chains, Freadman's concept of uptake, and, in particular, the relationship between the two. ${ }^{36}$ Freadman's concept has already been sketched out above, so at this point we need only to touch upon Swales'. He describes how genres are formed and, to a certain extent, formalized into chains in order for users to accomplish larger tasks. So, for instance, a part of the genre chain (or, more correctly, part of one of the genre chains) involved in arranging a scholarly conference is the one leading

35 Sune Auken, "Genre as Fictional Action," Nordisk Tidsskrift for Informationsvidenskab og Kulturformidling, 2/3 (2013): 19-28.

36 Swales, Research Genres, 18-20, Freadman, “Anyone for Tennis?” and "Uptake.” 
to the individual paper presentations. If successful, it runs approximately like this: ${ }^{37}$

\author{
Call for papers \\ paper proposal \\ Review meeting/interchange \\ Letter of acceptance \\ Paper draft from presenters \\ Letter from arrangers to participants with paper draft \\ Presentation \\ Discussion
}

The central difference compared to the concept of uptake is that a genre chain is formalized. Each genre, of course, is an uptake on the former, but one must move through the whole series in order to present one's paper correctly. Some of the steps are structurally optional, not all conferences require paper drafts to be submitted, and some of the steps can be short-circuited: One can (for whatever reason) refrain from sending one's paper draft for a conference which requires it, or one can talk for so long during the presentation that there is no room for discussion-or, alas, even longer if the session chair is unwilling to exert his or her mandate. But these short-circuits are shortcomings compared to the purpose of the genre chain. A successful fulfilment of the purpose of the genre chain requires that each step is completed in order.

Both concepts, uptake and genre chain, describe how genres relate to one another in a dynamic process, and both are necessary in order to describe the actual interchanges through genre. Seen from one angle, a genre chain is a formalized series of uptakes. Genre chains are bound; they move in a particular order, and relate to one another in a particular hierarchy. Uptakes can be more creative; an uptake can easily follow a chain, but it can also deviate from, turn, or twist the purpose of the chain. Also, it may be an uptake to insert one or more new genres into the process in an attempt to achieve a desired purpose. One may, for instance, attempt to use the genres "bribery" or "seduction" in order to be allowed to give a conference paper instead of following the chain described above. Creative uptakes of genre chains may be effective, and sometimes they can even trump the chains, but in many cases the given chain is by far the stronger, and creative uptakes of it are likely to fail.

This applies to everyday life. When moving into the literary field, however, we will expect to see genre chains and uptakes entering into a somewhat different relationship. As narrative texts tend to deal with exceptional social situations, they will contain exceptional uses of genre. Thus, we will find uptakes trumping chains on a regular basis. Accordingly, in interpretation we would, following

37 This is an abbreviated version of a similar chain drawn up by Swales himself. 
Swales and Freadman, be looking for the interaction and even interlocking of genre chains and uptakes. In interpreting through genre, we will look at the ways in which different actors handle these uptakes, how they choose between them, interpret, shape, or even manipulate them in order to suit their own social and communicative needs.

\section{RGS and Form Criticism}

The central concepts of RGS connect it with an important scholarly tradition in biblical studies: form criticism. There is an obvious parallel between the concept of the "recurrent rhetorical situation" central in RGS and the crucial place of the Sitz im Leben of a genre fundamental to the understanding of the Gattung in form criticism. $^{38}$

Given the limited contact between RGS and biblical studies, it should come as no surprise that little is written on the subject. In literary studies, the Sitz im Leben has been discussed by Hans Robert Jauss ${ }^{39}$ — though without reference to RGS as Jauss writes years before Miller-and the connection between it and the recurrent rhetorical situation of RGS has been noted by Beata Agrell. ${ }^{40}$ However, little seems to have been done beyond this, and nothing at the core of genre studies. The scope of the present article does not allow a deeper engagement with this question; a few notes comparing the two must suffice for now.

Apart from the obvious fact that form criticism typically has the ambition to assist in the reconstruction of the history of specific traditions and RGS has not, form criticism and RGS share a common understanding of the situatedness of genre. They both see genres as responses to social situations; that is, as ways to handle social needs and carry out social intentions. Thus, to understand a genre is, to a large extent, to understand the function it serves to its users, and the interpretation of any given genre therefore hovers between a rhetorical, an ethnographic, a historical, a literary, and a sociological approach.

However, the differences between the two approaches are quite obvious. I will, for now, touch on only two. The fundamental method of form criticism is a "linguistic textual analysis that may be applied both synchronically and dia-

38 For a more detailed discussion of form criticism see Klaus Koch, The Growth of the Biblical Tradition: The Form-Critical Method (London: Adam \& Charles Black, 1969) and Martin J. Buss, Biblical Form Criticism in its Context, JSOTSup 274 (Sheffield: Sheffield Academic Press, 1999).

39 Hans Robert Jauss, "Theory of Genre and Medieval Literature," in Toward an Aesthetic of Reception, trans. Timothy Bahti (Brighton: The Harvester Press, 1982), 102-104. Jauss' translator renders "Sizt im Leben" as "Locus in Life" (103).

40 Beata Agrell, "Genre and Working Class Fiction,” in S. Auken et al., Genre and ..., 286-327. 
cronically to texts in either written or oral form. ${ }^{341}$ It identifies textual regularities and works from these to establish the social situation of the genre, so the understanding of the genre is largely deductive. There are very practical reasons for this. In the words of James Muilenburg,

[p]erhaps more serious is the scepticism of all attempts to read a pericope in its historical context. The truth is that in a vast number of instances we are indeed left completely in the dark as to the occasion in which the words were spoken, and it is reasonable to assume that it was not of primary interest to the compilers of the traditions. $^{42}$

Consequently, form criticism aims to understand the genres through their Sitz im Leben, but can only get to it through an understanding of the genre. This leads to what Sellin has termed "literaturwissenschaftliche Paläontologie der christlichen Urgeschichte" ${ }^{33}$ and also brings the method dangerously close to circular reasoning. ${ }^{44}$

The RGS researchers' understanding of the social situation is more empirical. Their understanding of genre is emphatically not based on textual regularities, but on generic function. ${ }^{45}$ Miller's original article is mostly theoretical. But the subsequent studies branching out of the theory and terminology within the movement, have been working with analysable uses of genres in context. Some of these have been historical, ${ }^{46}$ but most are rhetorical, linguistic, ethnographic, or, if you will, ethno-rhetorical. ${ }^{47}$ Thus the concepts employed to describe the patterns and uses of genre have been developed in the description of how genres work in actual settings.

41 Marwin A. Sweeney, "Form Criticism," in To Each its Own Meaning: Biblical Criticisms and Their Application, ed. S. L. McKenzie and S. R. Haynes (Louisville: Westminster John Knox, 1999), 58.

42 James Muilenburg, "Form Criticism and Beyond," JBL 88 (1969): 6.

43 Gerhard Sellin, “'Gattung' und 'Sitz im Leben' auf dem Hintergrund der Problematik von Mündlichkeit und Schriftlichkeit synoptischer Erzählungen," EvT 50 (1990): 312.

44 Bultmann's hermeneutic statement of the relationship as a circular move between the "forms of the literary tradition" and "the influences operating in the life of the community" (Rudolf Bultmann, History of the Synoptic Tradition [Peabody: Hendrickson, 1963], 5) is quite valid, insofar as there is alternative source material available for the understanding of the life of the community. However, when this is not the case or to the degree that this is not the case, the circle loses its hermeneutic character.

45 Cf. Auken, "Utterance and Function."

46 For instance Charles Bazerman, Shaping Written Knowledge (Madison: The University of Wisconsin Press, 1988), Bazerman, "Systems of Genres"; Freadman, "Uptake"; and Laura Skouvig, "Genres of War: Informing a City," in J. Andersen, Genre Theory in Information Studies, 133-154.

47 Thus Devitt, "Intertextuality"; Schryer, "Records as Genre"; Russel, Rethinking Genre"; Winsor, "Ordering Work"; Paré, "Genre and Identity"; Heather MacNeil, "What Finding Aids Do: Archival Description as Rhetorical Genre in Traditional and Web-Based Environments," Archival Science Sciences 12 (2012): 485-500, and numerous other works. 
Second, being developed for the understanding of the Bible, the genres analysed by form criticism are parts of a larger utterance. The fundamental building blocks of form criticism are the "individual units of the tradition," 48 i.e., the genres embedded in the biblical texts on the level of the pericopes, whereas the larger units are seen as built up from these genres. The primary material of form criticism is thus below the level of the individual utterance. In contrast the topics chosen in contemporary genre studies are almost always above the level of the individual utterance, and only rarely do scholars move into the embedded genres that make up an utterance. This is more a difference of approach than a scholarly disagreement, but it is consequential none the less.

Due to the aforementioned differences, and others with them, the actual analytical work carried out in form criticism is closer to what is being done by philologists and literary scholars than to RGS, and comparing it to the other scholarly methods in contemporary genre studies would probably show even more fundamental differences. Yet, the second of the major differences mentioned above could also be seen as an obvious point of connection: Just as the Sitz im Leben of form criticism resembles the rhetorical situation in RGS, so, too, do the former's generic "units" (Gattungen) bear resemblance ${ }^{49}$ to the rhetorical genres of the latter. Furthermore, given the complexity of the Bible and the relative simplicity of most texts discussed by RGS, there will often be cases where the embedded genres discussed in form criticism are actually as complex as, or more complex than, the individual genres studied in RGS.

\section{Reading John through Genre}

In bringing the concepts of contemporary genre studies to the Gospel of John, we are-despite the above points of contact-by necessity translating and re-contextualizing a scholarly endeavour which has been developed in order to treat a different set of scholarly problems and which has at certain points been developed in opposition to literary genre studies. Therefore, the practice cannot be mainline RGS, but must develop new approaches that combine the scholarly insights of contemporary genre studies with those of other research traditions. What follows is a tentative attempt at applying such an approach.

One of the longer connected actions in John is the story of Jesus' capture, trial, and crucifixion (John 18-19). Here, we have a situation ripe with conflict, one in

48 Bultmann, History of the Synoptic Tradition, 3.

49 Resemblance is not identity, and an extensive comparative study of the different concepts would be required to unravel their precise relationship. However, the concepts are sufficiently related for the parallels drawn here. 
which a number of different actors try to achieve their own distinct purpose: The central actors in the passage are for our purposes here Jesus himself, the priests, the Ioudaioi, the disciples, the soldiers, and Pilate.

The social actions attempted by these actors are diverse. Not only do they not align smoothly, they are not even clearly opposed, or moving in opposite directions. To confuse matters even further, the passage is generically undermarked. Throughout the passage most utterances are simply described as something somebody "says"—not "threatens", "asks", "replies" or the like. So, for instance, the uptake presented by a question and reacted to by the answer is rarely marked as such. Though the genres at play in the passage are actually quite diverse, the text is subdued in its characterization of them.

The most obvious attempts at social action carried out through the two chapters are the endeavours of the Ioudaioi-and through them the priests-to get Jesus crucified, and Pilate's attempts to avoid having to pass the judgement for capital punishment. The two sides, then, are basically fighting over a genre, the sentence, and each of them is manoeuvring in order to achieve a certain kind of sentence. The generically challenging part of the process is that the Ioudaioi are looking to achieve a certain social aim, namely the execution of Jesus, that can only be fulfilled by Pilate who, in turn, is unwilling to order the execution-and is even unwilling to pass any kind of judgement on Jesus whom he considers innocent. The genres used by the Ioudaioi are reasonably straightforward: Accusations, demands, and threats. The threats are marked generically by the raising of their voices and by the fear that their words invoke in Pilate (19:8).

Generically speaking, what the Ioudaioi are trying to do is to set a genre chain in motion in the Roman administration which includes such moves as arrestaccusation-interrogation-conviction-execution. The evidence is weak, at best, but the social situation is strong.

Pilate is less straightforward. Cornelis Bennema claims that "Pilate is probably the most complex character in the Johannine narrative," ${ }^{\prime 5}$ and even if this may be overstating the case, at least the prefect's use of genre is rather complex. This may have to do with the fact that his situation is more muddled and his motives are more ambiguous. He does not want to execute Jesus, but he does not have the strength of conviction to match that of the Ioudaioi, and he is scared that the situation might backfire.

This makes him weak, despite his position as ruler. ${ }^{51}$ It also makes him a fascinating genre user. He reacts to a number of uptakes and, through both

50 Cornelis Bennema, Encountering Jesus: Character Studies in the Gospel of John, 2nd ed. (Minneapolis: Fortress Press, 2014), 337.

51 But see the alternate interpretations of Pilate in Bennema, Encountering Jesus and Andrew T. Lincoln, Truth on Trial: The Lawsuit Motif in the Fourth Gospel (Peabody: Hendrickson, 
standardized and individualized generic responses, he invites a number of uptakes. But he rarely, if ever, receives the responses he desires-even if he sometimes receives the responses his uses of genre invite. In this sense, for instance, his attempt to use the genre of the pardon to solve the problem is defeated by the demand of the Ioudaioi that he should pardon Barabbas (18:3940). Thus, the power of genre works against him: Though he finds Jesus innocent and, formally speaking, has the power to acquit him, Jesus ends up dead on the cross. In spite of his attempts to break the genre chain that leads to the execution, his uptakes are thwarted by the other actors.

Among these actors is, surprisingly, the accused man himself. Interestingly, from a point of view of genre as social action, Jesus himself seems to act very little. In fact, when first looking at this passage, I found that he was by far the dullest character, if understood as a genre user. On a closer look, however, he is in fact the most interesting one. Even during the initial arrest, Jesus conducts himself in discordance with the given genre. Jesus "takes charge of the situation by disclosing his own identity before anyone else is able to make a move." 52 The force dispatched to arrest him is absurdly large, including not just the guard force, but servants of the high priests and the Pharisees as well (18:3). Normally under circumstances such as these, resistance is futile. However, the prisoner does not even need to resist arrest; as soon as he identifies himself, the arresting forces stumble backwards and fall. Yet, despite the ease with which Jesus overpowers his would-be captors he still allows them to arrest him. He thus steps out of the given roles in the genre of the arrest. Rather than being the object of an arrest, he becomes the subject of it, and his apprehension is, effectively, more an event of his own making than something which is done to him. ${ }^{53}$

This turn of events continues in the trial scenes. The trial as genre determines the particular roles of its participants: One is attributed the role of the interrogator and judge, ${ }^{54}$ while the other-presumably unwillingly-assumes that of the defendant. The latter has the most to gain or lose, but he is also the person whose role is most severely restricted: In the genre chain of the trial, he has only one genre available to him: the answer to a question. This may be a general and overarching genre; however, its constraints are clearly demarcated: The interrogator's questions limit the possibilities as to what direction the answer may

2000), both of whom depict Pilate as a shrewd politician who uses the situation to his advantage.

52 Kasper Bro Larsen, Recognizing the Stranger: Recognition Scenes in the Gospel of John, BIS 93 (Leiden: Brill, 2008), 168.

53 Larsen, Recognizing the Stranger, 169.

54 This double role of interrogator and judge is, of course, unusual by modern standard, but seems quite natural in the text. 
take. This is a highly artificial situation, and it has every trait of what Paré describes as the "illusion of normalcy" in genres.

Jesus' replies, however, break the illusion of normalcy in the situation. Instead of replying as a person who is subject to another's authority and must justify himself to this other person, Jesus replies as a person of authority. In accordance with his role as a judge elsewhere in the Gospel (i.e., 5:22; 8:16; 9:39; and 12:2931), Jesus "puts his judge on trial regarding the truth," stance as participant in the trial genre. His uptakes on Pilate's questions are consistently unorthodox compared to the genre. He asks questions instead of answering, he also throws Pilate's questions back in his face and, at a certain point (19:10-11), he even denies his judge the power of judgement. Furthermore, the Gospel confirms this point through an ironic reversal. Inherent in Pilate's original question is an implied threat against Jesus: I have the power over your life, so you should comply with me, or you will be in danger. This threat is not just made by Pilate but is part and parcel of the interrogation as genre. The Gospel, however, proves Jesus right: He is executed despite Pilate's efforts, and thus his denial of Pilate's power to rule over life and death is confirmed.

Jesus talks as if Pilate is somehow at a disadvantage compared to him, and the prefect never gets what he desires from his prisoner. Accordingly, as a genre user Jesus does not comply with the role attributed to him by the genre and the rhetorical situation. He exhibits what might be termed "generic insubordination." According to what has previously been said in this article, it is unsurprising that he does not achieve the usual aim of the accused man in a trial: Acquittal.

However, the point remains that Jesus, as is well known, acts in accordance with a master plan beyond the comprehension of the other characters. He does not achieve social action in the usual sense through his genre use, but he achieves divine action instead. The master plan is clearly marked in the beginning of chapter 18 which details the arrest. It is also evident in Jesus' pre-knowledge of the entire process (18:5), his care to comply with his own prophecy (18:9), and in his explicit acceptance of the Father's cup (John 18:11). From this point of view, the other actors in the narrative are embedded in a divine, ironic structure.

From their own perspective, the other actors behave according to their own purposes, and thus, their success of failure can be measured according to a socially established understanding of success and failure: The Ioudaioi triumph, Pilate fails, and, from this perspective, Jesus pays the ultimate price for his inability to act in his own best interest. From another perspective, however, which

55 Lincoln, Truth on Trial, 129. 
is the perspective of the Gospel, the exchange is a path to Jesus' ultimate success; namely, the fulfilment of his-at once earthly and divine-purpose. ${ }^{56}$

This is quite evident in the crucifixion scene, which is, in John, less a scene of torture than of triumph. Jesus reinterprets the genre of the execution by taking it into his own hand. His genre-given role as victim is to suffer and die, but he remains active throughout. He knows when the purpose is fulfilled, asks for a drink in order to fulfil yet another bit of scripture, not because he is thirsty, and then-activelygives up the Spirit, as if by decision. Like Pilate and the Ioudaioi, the other actors in the scene play into the prophecies and thus help to fulfil them, even as they believe that they are acting independently. The stabbing of Jesus' dead body is one more confirmation of the divine purpose that has been carried out (19:34-36): "[T]he death of Jesus is more of a triumphal exit than a kathartic degradation."

All of this points to yet another genre towards which Jesus displays a loyalty that explains his otherwise aberrant behaviour as a genre user. This genre is, of course, the prophecy. The prophecy, as it appears here (5-6 times in chapters 18 and 19), is an earthly manifestation of a divine plan, established long before the events described, and possessing a transcendent reality beyond anything imagined by the other actors in the narrative. Jesus complies completely with this genre. This leads him to transcend all other generic purposes in order to fulfil the prophecies and thereby complete the divine plan expressed in them. Jesus fails to use genre as social action because he sees beyond this function to genre as divine action.

\section{Conclusion}

As should be evident from the analysis above, it is a quite apt metaphor when the editor of the present volume names John a "genre mosaic." The social genres involved in the trial scene-as well as the hidden, but stronger, genre of prophecy -interact through chains and uptakes to form a larger whole: The story of the arrest, interrogation, and execution of Jesus. They are stones and patterns in a mosaic, and, obviously, the story in chapters 18 and 19 must be understood in the larger context of the whole Gospel, and thus is only one pattern, albeit a very important one, within the larger context of the genre mosaic which is the Gospel of John.

56 In accordance with the concept of the "third 'law" described in Larsen, Recognizing, 179. Jesus is convicted as a criminal when the law of the Ioudaioi and the imperial law finally meet, but the conviction actually displays and fulfils his kinghood according to the divine law that Jesus himself follows. See also Lincoln, Truth on Trial, 123-138.

57 Mark W. G. Stibbe, John as Storyteller: Narrative Criticism and the Fourth Gospel, SNTSMS 73 (Cambridge: Cambridge University Press, 1990), 125. 
The basic assumption that underpins the metaphor of the genre mosaic is wellknown in genre research in much the same way as the idea of "genre bending" is a local expression of an established understanding in genre research. In general genre studies, the relationship between genres within a complex genre is usually expressed through Bakhtin's distinction between primary and secondary "speech genres." In Bakhtin's formulation, the complex genres (or "secondary speech genres") arise as combinations of simpler genres (or "primary speech genres"). These simpler genres lose part of their original character when they are used as building blocks, but they also add meaning to the overarching, secondary genrein keeping with the metaphor. The stones in the mosaic are seen less as individual stones than as parts of a mosaic, but their presence also constitutes the mosaic.

But although the underpinnings of the metaphor are known already, this does not make it any less relevant for the understanding of the Gospel. It poses a number of questions that are analytically relevant for the interpretation. What genres form the individual "stones" in the mosaic of the Gospel of John? How do these genres link up to form larger patterns? And how do these patterns in turn hinge upon one another to create the complete mosaic that is the Gospel of John? That these questions can be asked in relation to other texts as well does not render them any less relevant in the Johannine studies. In fact, the possibility of asking similar questions in relation to different texts opens up the possibility of comparative interpretations through genre.

Generic investigations in John need not be as literary in character, as the example given above. I read the gospel "as text" and only incidentally engage in contextual-or for that matter theological—subjects. This process can be carried out on a much deeper level, but given the state of contemporary genre studies even this would barely be scratching the surface. More directly functional perspectives will offer different challenges to an understanding of genre in the Gospel of John. The actual functionality of genres and genre patterns is frequently researched through interview techniques, and through different kinds of fieldwork, and even when this is not the case, the studies are strongly focused on a contextual interest in the actual use and significance of genres for the people who use them. Interviews and fieldwork are not terribly viable methods in historical biblical studies, and the questions which can be dealt with contextually will always be limited by the available source material. Accordingly, the approaches have to be different. But given the centrality of genre in human culture, understanding, and communication, there will be numerous points of connection-of which this brief article has touched upon but a very few. ${ }^{58}$

58 Aside from the editor of the present volume, whose insightful comments have been crucial for the article, I wish to thank Helle Bildsøe and Søren Holst, both from the University of Copenhagen, for their help with the present study. 